\title{
Great Neurosurgeon of India - Prof. Des Raj Gulati
}

\author{
M.K. Tewari ${ }^{1}$ \\ ${ }^{1}$ Department of Neurosurgery, PGIMER, Chandigarh, Punjab, India
}

Indian J Neurosurg 2018;7:171-172

Prof. Des Raj Gulati graduated from K.E. Medical College, Lahore, but had to shift to Amritsar at the time of Indian independence. He did his Master in Surgery from Government Medical College, Amritsar, and thereafter worked in Punjab Medical Services for approximately 5 years. He was selected for neurosurgery training under the Colombo Plan in 1957 and therefore moved to Montreal Neurological Institute (MNI) in Canada. There he worked under stalwarts like Prof. Wilder Penfield, Prof. Theodore Rasmussen, and Prof. William Cone. At Montreal, Dr. P.N. Tandon, Dr. V.S. Dave, and Dr. D.N. Dadhich were his Indian colleagues.

Dr. Gulati was involved in research on brain edema with Dr. Hanna Pappius, and their publication on the subject was considered a landmark at that time. He also obtained a diploma in neurosurgery from McGill University, Montreal. He returned from Canada in 1961 and was soon appointed as an assistant professor of neurosurgery at Post Graduate Institute of Medical Education and Research (PGIMER), Chandigarh, an assignment he joined in 1962. He was to become a pioneer neuroscientist and founding father of Neurosciences in north-west India.

Soon after his joining PGIMER in 1962 as an assistant professor, the PGIMER administration realized that he was an old head on young shoulders and therefore gave him the responsibility to start both the departments of neurology and neurosurgery. He did this with aplomb and made them rise to national eminence. His keen interest in treating seizure disorders spurred him to procure an electroencephalogram (EEG) machine in 1966, and start a seizure clinic during his early years at PGIMER. Dr. Gulati had a keen interest in research. His pioneering experimental work on brain edema with Dr. Hanna Pappius, published in 1963, has been widely quoted. Back home, he continued with this practice and spent time in the pathology laboratory even in late 1960s despite his clinical commitments.

Dr. Vimla Virmani helped him in neurology during the years 1965 to 1967 . He continued to work without any rest till Prof. J.S. Chopra joined in 1968. After Prof. J.S. Chopra's joining in neurology, Dr. Gulati could concentrate exclusively on the development of neurosurgery. A year later, Prof. V.K. Kak joined the neurosurgical faculty, and thereafter
Address for correspondence M.K. Tewari, Department of Neurosurgery, PGIMER, Chandigarh, 160012, India (e-mail: manojktewari@gmail.com).
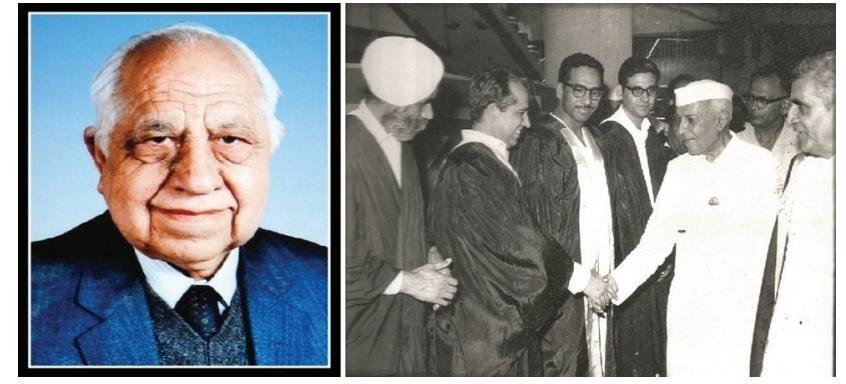

Prof. Des Raj Gulati (1936-2003)

the department took off. Though gentle and kind hearted, Dr. Gulati was a hard task master at the workplace. Dr. Gulati was initially the head of neurosurgery unit in the undivided department of surgery. He was instrumental in carving out the department of neurosurgery from general surgery in 1978. Two years later, in 1980, he was elected unopposed as President of Neurological Society of India. He was also elected as a Fellow of National Academy of Medical Science the same year. He served as a member and was on the panel of boards of several leading national academic organizations including ICMR, National Medical Academy, etc. He served as the Dean of PGIMER from 1980 to 1983 and held the charge of acting Director of PGIMER between Mach 1981 and November 1981. Dr. Gulati was conferred the rank of Honorary Consultant to the Armed Forces.

Dr. Y.S. Bhandari, Dr. K.S. Mann, and Dr. S.N. Dhaliwal joined as registrars with Dr. Gulati in the mid-1960s. He mentored registrars so well that Dr. K.S. Mann further continued his neurosurgery training in London, and later returned as a faculty member at PGIMER for some time. Dr. Ved Prakash Sachdev, who had joined as an assistant professor of otorhinolaryngology at PGIMER, was deputed to work in the department of neurosurgery. He developed such a keen interest in neurosurgery that he enrolled as the first candidate for the degree of M.Ch. (Neurosurgery) under Prof. Gulati and completed his neurosurgery training in 1968. The pupils who completed M.Ch. in neurosurgery under his able guidance were Dr. K.C. Pani and Dr. Damodar Rout. A large number of his pupils went on to head the departments at various centers in India and abroad. 
Dr. Gulati was a great academician and had a passion for research. He had to rely largely on detailed history and clinical examination to reach the possible diagnosis, with the help of carotid angiography, ventriculography, pneumoencephalography, and myelography. His clinical record documentation was exemplary, and the same can be said of his EEG reporting. He was a visionary and a great scientist, not only in neurosurgery but he had an excellent knowledge of neurology as well, a legacy of his training at the MNI, a pioneering neurological institute in the world. With his vision, he led the department to achieve national and international repute.

Over and above, Prof. D.R. Gulati was an excellent human being. He was a fatherly figure who was respected by all his pupils, staff working with him, and his colleagues. He was full of human values. He was a magnanimous person who did not believe in criticizing or speaking ill of anyone. His wife complemented him admirably, and together they were an ideal couple with affable personalities and admirable hosts. He superannuated from PGIMER, Chandigarh, on August 31, 1983. Even after his retirement, he often used to visit the department, attend Saturday morning clinical rounds, and interact with younger students on whom he left his mark. He was a personality who was loved and respected not only by his associates, but equally by his juniors, students, and staff and served as a source of motivation for all. The society, the institution, and the department where Dr. Gulati served will always remain grateful to him for his contributions and will always try to carry forward his legacy. 